\title{
The Influence of Carbon Dioxide and Oxygen Partial Pressures on Chlorella Growth in Photosynthetic Steady-state Cultures
}

\author{
By MARGARET WATTS PIRT AND S. JOHN PIRT* \\ Microbiology Department, Queen Elizabeth College, Campden Hill, London W8 7 AH
}

(Received 13 December 1979)

The effects of $\mathrm{O}_{2}$ and $\mathrm{CO}_{2}$ partial pressures in the range 0 to 1 atm on the maximum growth rate, starch production and photosynthetic efficiencies of growing cultures of Chlorella were determined. Stepwise increases of about $0.2 \mathrm{~atm}$ in the partial pressure of either gas inhibited growth, often completely. In contrast, gradual increases (steps of less than $0 \cdot 1$ atm) in the partial pressure of either gas maintained growth, and the cultures became adapted to high partial pressures. Adapted cultures tolerated $0.6 \mathrm{~atm} \mathrm{CO}_{2}$ or $0.8 \mathrm{~atm} \mathrm{O}_{2}$ without any growth inhibition as measured by maximum specific growth rate. Also, starch production was little affected by the increases in $\mathrm{O}_{2}$ or $\mathrm{CO}_{2}$ partial pressures.

The photosynthetic efficiency, as measured by the growth yield from light ( 400 to $700 \mathrm{~nm}$ wavelength) absorbed, and the maintenance energy were the same in adapted cultures with the $\mathrm{O}_{2}$ partial pressure at either 0.2 or $0.8 \mathrm{~atm}$. The maximum growth yield from light was $0.0172 \mathrm{~g} \mathrm{~kJ}^{-1}$, with $95 \%$ confidence limits of 0.0156 to 0.0189 . The maintenance energy was $1.27 \mathrm{~kJ}$ (g dry wt) $)^{-1} \mathrm{~h}^{-1}$, with $95 \%$ confidence limits of 0.89 to 1.65 . The photosynthetic efficiency in light-limited cultures was $36.5 \%$, with $95 \%$ confidence limits of 33 to $40 \%$.

\section{INTRODUCTION}

Despite the central roles of $\mathrm{CO}_{2}$ and $\mathrm{O}_{2}$ in photosynthesis, knowledge of the effects of the partial pressures of these gases on photosynthesis is conflicting or vague. Warburg (1920) first reported that increasing $\mathrm{O}_{2}$ partial pressure above 0.02 atm reversibly inhibited photosynthesis as measured by $\mathrm{O}_{2}$ evolution by 'resting', that is, non-growing algal cell suspensions over a 30 min period. Björkman (1966) found with Chlorella that there was no measurable inhibition of $\mathrm{CO}_{2}$ fixation by $\mathrm{O}_{2}$. Turner \& Brittain (1962) referred to the $\mathrm{O}_{2}$ inhibition of photosynthesis as the 'Warburg effect', but these authors considered exclusively short term (about $60 \mathrm{~min}$ ) effects in resting cell suspensions.

Myers (1953) reported that algal photosynthesis is inhibited by an increase in $\mathrm{CO}_{2}$ partial pressure above $0.05 \mathrm{~atm}$. In addition, $\mathrm{CO}_{2}$ has been reported as antagonizing the Warburg effect (Turner \& Brittain, 1962), although this effect seems highly variable.

In our experience, step changes of more than a few per cent in $\mathrm{CO}_{2}$ or $\mathrm{O}_{2}$ partial pressure inhibited growth of a continuous culture of Chlorella. The cells, however, became adapted to tolerate the increased partial pressures of the gases when the partial pressure was gradually increased over two or three generations of the Chlorella cells. This adaptation to the high partial pressures was greatly facilitated by application of chemostat continuous flow culture.

According to Tolbert (1974), 'photorespiration' is defined as 'respiration uncoupled to ATP production' in photosynthetic plants or algae. Tolbert stated that 'photorespiration increases with increase in $p_{\mathrm{O}_{2}}$ ' but again the observations referred to step changes in gas partial pressure in resting cell suspensions. Since determination of the photorespiration rate 
involved decreasing the $p_{\mathrm{CO}_{2}}$ to the compensation point when the $\mathrm{CO}_{2}$ uptake rate equals the production rate, the photorespiration could be an artefact. Also the decrease in the $\mathrm{CO}_{2}$ partial pressure could have stimulated endogenous metabolism. 'Resting cells' are known to respond in this way to the withdrawal of a substrate (Pirt, 1975).

The specific rate of light absorption $\left[q, \mathrm{~kJ}(\mathrm{~g} \text { dry wt })^{-1} \mathrm{~h}^{-1}\right]$ during growth of a light-limited culture is expected to accord with the bioenergetics equation (Pirt, 1975): $q=\left(\mu / Y_{\mathrm{G}}\right)+m$, where $\mu$ is the specific growth rate $\left(\mathrm{h}^{-1}\right), Y_{\mathrm{G}}$ is the true growth yield (g dry wt kJ-1) and $m$ is the maintenance energy $\left[\mathrm{kJ}(\mathrm{g} \text { dry wt })^{-1} \mathrm{~h}^{-1}\right]$. Any photorespiration term would affect $m$, and a change in $m$ can be determined by a plot of $q$ against $\mu$ (Pirt, 1975). This test is best applied by varying $\mu$ in a chemostat culture (Pirt, 1975). In energy conservation it is important to know not only whether the $\mathrm{O}_{2}$ or $\mathrm{CO}_{2}$ partial pressures inhibit growth, but also whether they have any effect on the maximum growth yield $\left(Y_{\mathrm{G}}\right)$ and the maintenance energy $(m)$.

The present paper reports the growth inhibitory effect of high $\mathrm{O}_{2}$ and $\mathrm{CO}_{2}$ in partial pressures up to 0.95 atm for $\mathrm{O}_{2}$ and $1 \mathrm{~atm}$ for $\mathrm{CO}_{2}$, as measured by the maximum specific growth rate $\left(\mu_{\mathrm{m}}\right)$ of adapted Chlorella cells in chemostat cultures. Also, the photosynthetic efficiencies and maintenance energies at low and high $\mathrm{O}_{2}$ partial pressures are compared.

Whereas previous studies on the effects of $\mathrm{O}_{2}$ and $\mathrm{CO}_{2}$ on photosynthetic Chlorella cells have used almost entirely 'resting cells', the work this paper presents is concerned with growing cells. A preliminary account of the results has been presented (Watts Pirt \& Pirt, 1979).

\section{METHODS}

Organism. A pure culture of Chlorella 211/8k from the Culture Centre for Algae and Protozoa, Cambridge, was grown at $37^{\circ} \mathrm{C}$ and with the $\mathrm{pH}$ controlled at 6.5 to 6.7 . Stock cultures were maintained on a urea/mineral salts medium under $5 \% \mathrm{CO}_{2}$ in air as described previously (Watts Pirt \& Pirt, 1977).

Chemostat culture. The culture vessel was a stirred illuminated chemostat, as previously outlined (Watts Pirt \& Pirt, 1977) with a $67 \mathrm{~mm}$ inside diameter and $65 \mathrm{~mm}$ culture depth at the side-arm overflow, and a working volume of $180 \mathrm{ml}$.

Gas supply. The chosen gas composition was supplied to the chemostat culture at a flow rate of $40 \mathrm{ml}$ $\min ^{-1}$. The required mixtures in terms of $\mathrm{CO}_{2}$ and $\mathrm{O}_{2}$, in air or $\mathrm{N}_{2}$, were achieved by mixing the appropriate components from a range of supply cylinders containing the following gases: pure $\mathrm{CO}_{2}, 5 \% \mathrm{CO}_{2}$ in air, $95 \% \mathrm{O}_{2}$ plus $5 \% \mathrm{CO}_{2}, 80 \% \mathrm{O}_{2}$ plus $20 \% \mathrm{CO}_{2}$, and nitrogen. Flow controllers (G. A. Platon) and flowmeters (Rotameter Co.) were used to regulate individual gas feed rates, before combining gases to pass into the culture vessel.

Media. For growth under nitrogen limitation and for the determination of the effect of $\mathrm{CO}_{2}$ and $\mathrm{O}_{2}$ on growth, medium A8 was used, with composition as described by Watts Pirt \& Pirt (1977), except that $\mathrm{NaVO}_{3}$ was included at $0.05 \mathrm{mg} \mathrm{l}^{-1}$. For light-limited growth in the chemostat, medium A19 of the following composition was used $\left(\mathrm{g} \mathrm{l}^{-1}\right)$ : urea, $1.87 ; \mathrm{KH}_{2} \mathrm{PO}_{4}, 1.45 ; \mathrm{MgSO}_{4} .7 \mathrm{H}_{2} \mathrm{O}, 0.675 ; \mathrm{CaCl}_{2} .2 \mathrm{H}_{2} \mathrm{O}, 0.02$; and trace element solution at double the level of $\mathrm{A} 8$, and including $\mathrm{NaVO}_{3}$ at $0 \cdot 1 \mathrm{mg} \mathrm{^{-1 }}$ and $\mathrm{NiSO}_{4} \cdot \mathrm{H}_{2} \mathrm{O}$ at $0.0125 \mathrm{mg} \mathrm{l}^{-1}$.

Analytical methods. The methods of measurement of total cell dry weight, starch and urea were as described by Watts Pirt \& Pirt (1977). Biomass was determined as total cell dry weight, designated $\bar{x}$ in steady-state conditions. From the measurement of starch in the biomass $(\bar{s})$, it was possible to calculate the value of the real biomass, designated $(\bar{x}-\bar{s})$.

Determination of maximum specific growth rate $\left(\mu_{\mathrm{m}}\right)$. Both the 'washout method' in the chemostat culture (Pirt, 1975) and batch culture were applied to determine the maximum specific growth rate $\left(\mu_{m}\right)$. The washout method was found to cause an underestimation when $\mathrm{CO}_{2}$ in the gas phase exceeded $0.2 \mathrm{~atm}$, and similarly when $\mathrm{O}_{2}$ approached $0.6 \mathrm{~atm}$. This may have been due to transient inhibitory effects at the high $\mathrm{CO}_{2}$ and $\mathrm{O}_{2}$ levels. At these high levels, the $\mu_{m}$ was checked by batch culture immediately after the end of the washout period when apparently the transient inhibition was overcome.

Measurement of incident light on the chemostat, and calorific value of the biomass. The methods of Pirt et al. (1980) were used in the determination of light-limited biomass production parameters and calorific value of the biomass. From the evaluation of light input and energy content of the biomass as its calorific value, it was possible to determine the photosynthetic efficiency of the light-limited cultures. 


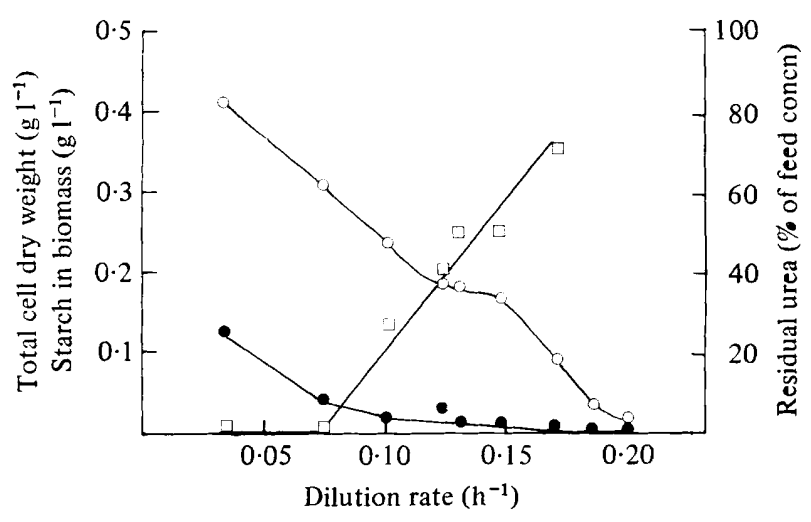

Fig. 1. $\mathrm{CO}_{2}$ limitation of growth of Chlorella in steady-state chemostat culture in medium A8 with a feed of 0.005 atm $\mathrm{CO}_{2}$ in air at $40 \mathrm{ml} \mathrm{min}^{-1}$ in a $180 \mathrm{ml}$ culture: $O$, total cell dry weight; , starch content of biomass, $\square$, residual urea.

\section{RESULTS}

\section{$\mathrm{CO}_{2}$ limitation of growth}

With a feed of $0.005 \mathrm{~atm} \mathrm{CO}_{2}$ in air at $40 \mathrm{ml} \mathrm{min}^{-1}$ to a chemostat culture of Chlorella, $\mathrm{CO}_{2}$ limitation of growth was observed at dilution rates above $0.07 \mathrm{~h}^{-1}$, in a $180 \mathrm{ml}$ culture vessel with a shallow vortex (Fig. 1). Residual urea was detected at dilution rates above $0.07 \mathrm{~h}^{-1}$. At dilution rates of $0.03 \mathrm{~h}^{-1}$ and $0.07 \mathrm{~h}^{-1}$ the starch content of the biomass was lower than under $\mathrm{CO}_{2}$-sufficient conditions.

The calculation of the output rate of total biomass $(D \bar{x})$ confirmed $\mathrm{CO}_{2}$ limitation of growth over the dilution rate $(D)$ range 0.07 to $0.15 \mathrm{~h}^{-1}$ (Fig. 2), where the biomass output rate was constant at about $0.024 \mathrm{~g}$ biomass $\mathrm{I}^{-1} \mathrm{~h}^{-1}$, under a constant flow rate of $\mathrm{CO}_{2}$. Above $0 \cdot 15 \mathrm{~h}^{-1}$, washout of the culture was approached.

A carbon balance was calculated to compare total carbon input, as $\mathrm{CO}_{2}$ plus the carbon input in the urea feed, with the output of carbon in the biomass. The $\mathrm{CO}_{2}$ dissolved in the culture feed was calculated and deduced to be negligible. Over the dilution rate range of 0.07 to $0.146 \mathrm{~h}^{-1}$, the carbon input rate $\left(\mathrm{CO}_{2}+\right.$ urea carbon) ranged from 0.555 to 0.564 $\mathrm{mmol} \mathrm{h}^{-1}$, and the carbon in biomass output rate ranged from 0.16 to $0.175 \mathrm{mmol} \mathrm{h}^{-1}$. Therefore, in this culture system, when growth was carbon limited, around 30 to $31 \%$ of the supplied carbon was utilized.

\section{Growth of Chlorella in $\mathrm{CO}_{2}$ up to $1 \mathrm{~atm}$}

Steady-state cultures of Chlorella were obtained in the chemostat with $\mathrm{CO}_{2}$ partial pressures up to $1 \mathrm{~atm}$ (in air) under a gas flow rate of $40 \mathrm{ml} \mathrm{min}-1$ in the $180 \mathrm{ml}$ vessel. In order to reach steady-state conditions with $\mathrm{CO}_{2}$ above $0.3 \mathrm{~atm}$ it was essential to allow a period of adaptation by waiting for at least four to five volumes of culture to pass through the system. When the $\mathrm{CO}_{2}$ partial pressure was raised between steady states, there was a maximum stepwise increase of $0.1 \mathrm{~atm}$ in order to avoid inhibition of the culture before it had become adapted to the new $\mathrm{CO}_{2}$ level. The culture was then allowed to adapt to this level for 0.75 to 1 volume changes in the chemostat before the $\mathrm{CO}_{2}$ partial pressure was further increased.

The maximum specific growth rate of the Chlorella cultures was measured by the washout method applied to a culture that had been adapted to the particular $\mathrm{CO}_{2}$ level, and confirmed consecutively by batch culture. Above $0.2 \mathrm{~atm} \mathrm{CO}_{2}$, the maximum growth rate measured by washout was less than in the consecutive batch culture, due to transient 


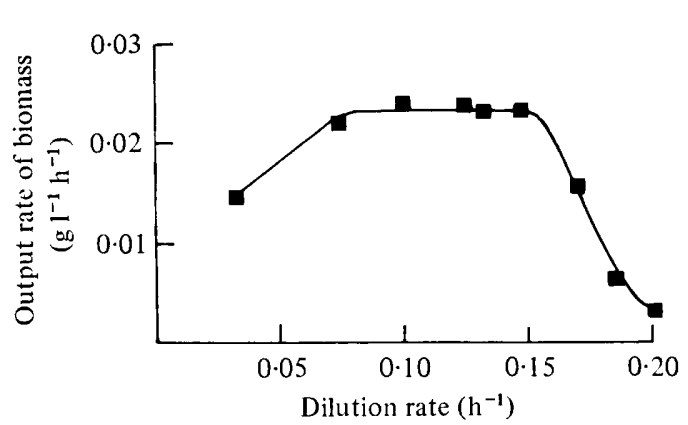

Fig. 2

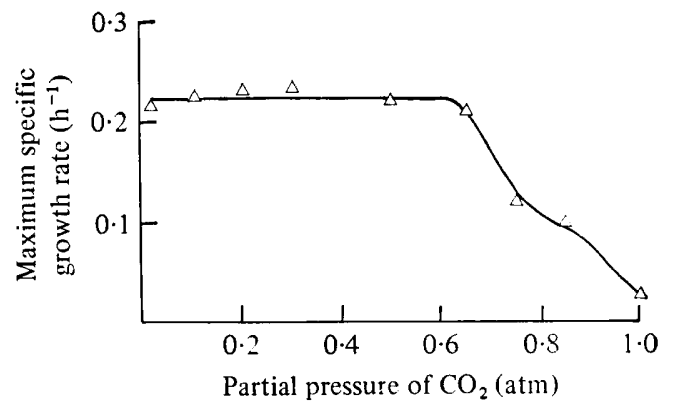

Fig. 3

Fig. 2. Output rate of Chlorella biomass (total $g$ cell dry wt $\mathbf{1}^{-1} \mathbf{h}^{-1}$ ) in a steady-state chemostat culture under 0.005 atm $\mathrm{CO}_{2}$ in air.

Fig. 3. Effect of partial pressure of $\mathrm{CO}_{2}$ up to 1 atm on the maximum specific growth rate of adapted Chlorella cells, with a $\mathrm{CO}_{2}$ in air flow of $40 \mathrm{ml} \mathrm{min}^{-1}$ in a $180 \mathrm{ml}$ chemostat.

$\mathrm{CO}_{2}$ inhibition. Steady-state cultures were obtained in $1 \mathrm{~atm} \mathrm{CO}_{2}$ with dilution rates up to $0.03 \mathrm{~h}^{-1}$.

Figure 3 shows that the maximum specific growth rate of Chlorella did not decrease until the $\mathrm{CO}_{2}$ pressure exceeded $0.65 \mathrm{~atm}$, and fell by $85 \%$ at $1 \mathrm{~atm}$.

\section{Influence of partial pressure of $\mathrm{CO}_{2}$ on starch production}

The specific rate of starch production in steady-state culture was measured at a dilution rate of $0 \cdot 11 \mathrm{~h}^{-1}$ in a range of $\mathrm{CO}_{2}$ partial pressures. At this dilution rate, starch production was not affected until the $\mathrm{CO}_{2}$ pressure exceeded $0.6 \mathrm{~atm}$ (Fig. 4).

\section{Influence of partial pressure of $\mathrm{O}_{2}$ on maximum specific growth rate}

If pure $\mathrm{CO}_{2}$ were supplied to a photosynthesizing culture, the $\mathrm{O}_{2}$ partial pressure in the culture could approach 1 atm. Hence, it was necessary to determine whether such increased $\mathrm{O}_{2}$ levels are inhibitory to Chlorella growth.

Chlorella cultures were adapted to increased levels of $\mathrm{O}_{2}$ in continuous flow culture by gradually raising the partial pressure of $\mathrm{O}_{2}$ in steps of no more than $0.2 \mathrm{~atm}$, and allowing the culture to stabilize at the new level with the passage of at least three to four volumes of nutrient through the chemostat to ensure steady-state conditions had been reached. Gas flow was controlled at $40 \mathrm{ml} \mathrm{min}{ }^{-1}$ with $\mathrm{CO}_{2}$ at $0.05 \mathrm{~atm}$; the pressure was made up to 1 atm with $\mathrm{N}_{2}$.

There was no reduction in maximum specific growth rate until the $\mathrm{O}_{2}$ pressure exceeded $0.8 \mathrm{~atm}$ (Fig. 5). The maximum specific growth rate was measured by washout and batch culture, and the two measurements corresponded until the partial pressure of $\mathrm{O}_{2}$ reached $0.65 \mathrm{~atm}$, when the washout value was $30 \%$ lower than in the consecutive batch culture. As the measurements were run consecutively, it was assumed that the $\mathrm{O}_{2}$ transiently became inhibitory during washout.

Growth of Chlorella in 0.2 atm $\mathrm{CO}_{2}$ plus 0.8 atm $\mathrm{O}_{2}$

In the photosynthetic production of biomass and starch by in vitro cultures of Chlorella, it would be feasible to control the supply rate of pure $\mathrm{CO}_{2}$ feed to the culture such that the exit gas would be significantly enriched in the photosynthetically produced $\mathrm{O}_{2}$. For example, if the $\mathrm{CO}_{2}$ were supplied at a rate such that $80 \%$ was used, then the exit gas would contain $0.2 \mathrm{~atm}$ residual $\mathrm{CO}_{2}$ and $0.8 \mathrm{~atm} \mathrm{O}_{2}$. As well as reducing the gas flow rate required, this would constitute a means of photosynthetic production of pure $\mathrm{O}_{2}$ if the residual $\mathrm{CO}_{2}$ were scrubbed out. 


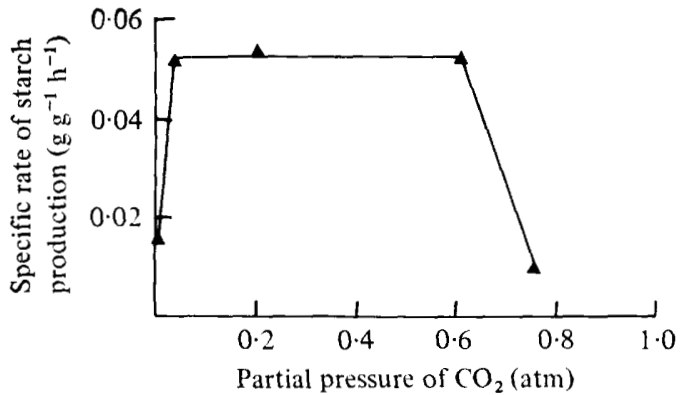

Fig. 4

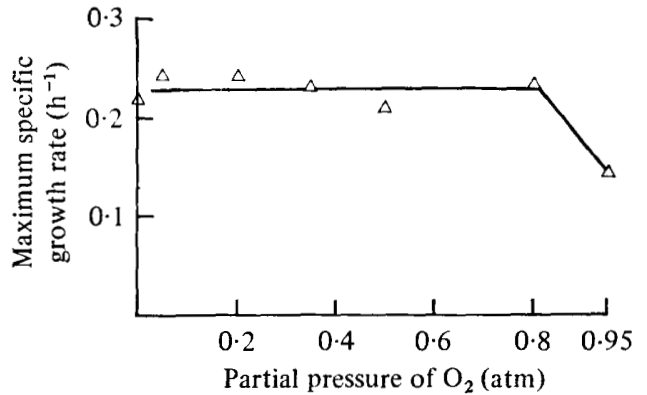

Fig. 5

Fig. 4. Effect of $\mathrm{CO}_{2}$ partial pressure on the specific rate of starch production [g starch (g cell real biomass $)^{-1} \mathrm{~h}^{-1}$ ] in a chemostat culture of Chlorella under nitrogen-limited growth at a dilution

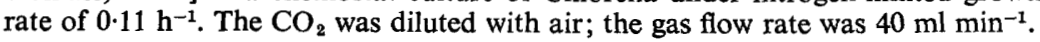

Fig. 5. Maximum specific growth rate of adapted cultures of Chlorella in $\mathrm{O}_{2}$ partial pressures up to $0.95 \mathrm{~atm}$, with $\mathrm{CO}_{2}$ maintained at $0.05 \mathrm{~atm}$. The gas pressure was made up to 1 atm with $\mathrm{N}_{2}$; the gas flow rate was $40 \mathrm{ml} \mathrm{min}^{-1}$.

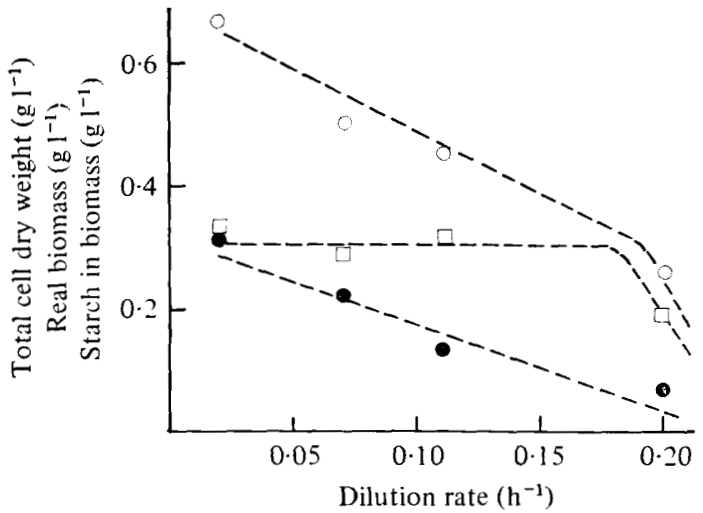

Fig. 6. Biomass and starch production by Chlorella in $0.2 \mathrm{~atm} \mathrm{CO}_{2}$ plus 0.8 atm $\mathrm{O}_{2}: \bigcirc$, total cell dry weight; $O$, starch in biomass; $\square$, real biomass. The measurements are compared with results previously obtained (Watts Pirt \& Pirt, 1977) which are shown by the dashed lines and represent biomass and starch production in 0.05 atm $\mathrm{CO}_{2}$ in air.

Therefore, the behaviour of Chlorella was followed in a $180 \mathrm{ml}$ chemostat culture supplied with $0.2 \mathrm{~atm} \mathrm{CO}_{2}$ and $0.8 \mathrm{~atm} \mathrm{O}_{2}$ at $40 \mathrm{ml} \mathrm{min}-1$, over a range of dilution rates to compare steady-state levels of biomass and starch with those under $0.05 \mathrm{~atm} \mathrm{CO}_{2}$ in air. As seen in Fig. 6, there was no inhibition of growth of Chlorella in 0.2 atm $\mathrm{CO}_{2}$ plus $0.8 \mathrm{~atm} \mathrm{O}_{2}$.

\section{Determination of maximum photosynthetic efficiency of Chlorella cultures in 0.2 atm $\mathrm{CO}_{2}$ plus 0.8 atm $\mathrm{O}_{2}$}

Although it was confirmed that photosynthetic Chlorella cultures could be grown in an atmosphere of $0.2 \mathrm{~atm} \mathrm{CO}_{2}$ plus 0.8 atm $\mathrm{O}_{2}$, it was necessary to measure the photosynthetic light uptake rates by steady-state cultures under light-limited growth and to calculate the maximum photosynthetic efficiency for comparison with that in cultures with $0 \cdot 1 \mathrm{~atm} \mathrm{CO}_{2}$ in air. With the intention of producing biomass, starch and, in addition, pure $\mathrm{O}_{2}$ from a pure $\mathrm{CO}_{2}$ feed to a photosynthesizing algal culture, a decrease in the photosynthetic efficiency would have reduced the economic potential of the system. 
The specific rate of light uptake by Chlorella was determined over a range of dilution rates. In each light-limited steady-state the biomass was measured and the specific rate of light uptake $(q)$ was calculated as $I . a / v . x$, where $I$ was the incident light intensity, $a$ was the illuminated area and $v$ the culture volume. The graph of $q$ against $\mu$ gave a straight line relationship. Linear regression analysis of the results both with $0.2 \mathrm{~atm} \mathrm{CO}_{2}$ plus $0.8 \mathrm{~atm}$ $\mathrm{O}_{2}$, and with $0 \cdot 1$ atm $\mathrm{CO}_{2}$ in air, gave straight line relationships, with no significant differences calculated at $95 \%$ confidence limits. From the slope of the lines, the maximum growth yield on light $\left(Y_{\mathrm{G}}\right)$ was found to be $0.0172 \mathrm{~g} \mathrm{~kJ}^{-1}(95 \%$ confidence limits 0.0156 to $0.0189 \mathrm{~g} \mathrm{~kJ}^{-1}$ ). From the intercept, the value of the maintenance coefficient on light was $1.27 \mathrm{~kJ} \mathrm{~g}^{-1} \mathrm{~h}^{-1}\left(95 \%\right.$ confidence interval 0.89 to $\left.1.65 \mathrm{~kJ} \mathrm{~g}^{-1} \mathrm{~h}^{-1}\right)$.

The calorific value of light-limited Chlorella biomass was found to be $21.15 \mathrm{~kJ} \mathrm{~g}^{-1}$, corrected for the nitrogen content (Kersting, 1972). Therefore, the maximum photosynthetic efficiency of light uptake by Chlorella, which was the product of $Y_{G}$ and the calorific value, was calculated to be $36.5 \%$ (95\% confidence limits 33 to $40 \%$ ).

\section{DISCUSSION}

The outstanding feature of the experiments reported here is the ability of growing Chlorella cells to adapt to high partial pressures of $\mathrm{CO}_{2}$ or $\mathrm{O}_{2}$ which, the literature suggests, can be totally inhibitory to resting cell photosynthesis. It is clear that almost total inhibition will occur transiently in the growing culture when the $\mathrm{CO}_{2}$ or $\mathrm{O}_{2}$ partial pressures are increased in large steps. The adaptation in the growing culture is assumed to be a phenotypic change since it could occur in three to four generations which would be inconsistent with selection of mutant cells. The nature of the adaptation is unknown.

It has been suggested that inhibition of ribulose bisphosphate carboxylase may be responsible for the $\mathrm{O}_{2}$ and $\mathrm{CO}_{2}$ effects (Laing et al., 1974). The activity of ribulose bisphosphate carboxylase in the growing culture could be relevant to elucidation of the molecular basis of the adaptation.

The constancy of the maximum growth yield $\left(Y_{\mathrm{G}}\right)$ and the maintenance energy $(m)$ with an increase in the $\mathrm{O}_{2}$ partial pressure to $0.8 \mathrm{~atm}$ indicates that Chlorella does not contain any metabolic site which is made inefficient by oxidation at the high $\mathrm{O}_{2}$ partial pressures. Since photorespiration would be included in the maintenance energy, it follows that photorespiration, if it existed, was unaffected by the increased $\mathrm{O}_{2}$ pressure in the adapted cell.

\section{REFERENCES}

BJöRKMAN, O. (1966). The effect of oxygen concentration on photosynthesis in higher plants. Physiologia plantarum 19, 618-633.

Kersting, K. (1972). A nitrogen correction for calorific values. Limnology and Oceanography 17, 643-644.

Laing, W. A., Ogren, W. L. \& Hageman, R. H. (1974). Regulation of soybean net photosynthetic carbon dioxide fixation by the interaction of carbon dioxide, oxygen and ribulose 1,5-diphosphate carboxylase. Plant Physiology 54, 678-685.

MYERS, J. (1953). Growth characteristics of algae in relation to the problems of mass culture. In Algal Culture, pp. 37-54. Edited by J. S. Burlew, Washington, D.C.: Carnegie Institution of Washington, Publication 600.

PIRT, S. J. (1975). Principles of Microbe and Cell Cultivation. Oxford: Blackwell Scientific Publications.

PIRT, S. J., Lee, Y. K., Richmond, A. \& WAtTs PIRT, M. (1980). The photosynthetic efficiency of Chlorella biomass growth with reference to solar energy utilization. Journal of Chemical Technology and Biotechnology 30, 25-34.

Tolbert, N. E. (1974). Photorespiration. In Algal Physiology and Biochemistry, pp. 474-504. Edited by W. D. P. Stewart. Oxford: Blackwell Scientific Publications.

Turner, J. S. \& Brittain, E. G. (1962). Oxygen as a factor in photosynthesis. Biological Reviews 37, 130-170.

WARBURG, O. (1920). UUber die Geschwindigkeit der photochemischen Kohlensäurezersetzung in lebenden Zellen. Biochemische Zeitschrift 103, 188-217.

Watts PIRT, M. \& PIRT, S. J. (1977). Photosynthetic production of biomass and starch by Chlorella in chemostat culture. Journal of Applied Chemistry and Biotechnology 27, 643-650.

Watts PIRT, M. \& PIRT, S. J. (1979). The influence of carbon dioxide and oxygen partial pressures on the growth of Chlorella. Photobiological production of pure oxygen and biomass. Society for General Microbiology Quarterly 6, 92-93. 